\title{
A cost-effective ultra-high throughput space-based optical link
}

Emile Haddad, Hamid Limodehi, Hongxin Chen, Francois Gonthier, Greg Schinn, et al.

Emile Haddad, Hamid Limodehi, Hongxin Chen, Francois Gonthier, Greg Schinn, Michel Corriveau, Dmitri Snejco, QiYang Peng, Kamel Tagziria, Wallace Clements, "A cost-effective ultra-high throughput space-based optical link," Proc. SPIE 11852, International Conference on Space Optics - ICSO 2020, 118525R (11 June 2021); doi: 10.1117/12.2600011

SPIE Event: International Conference on Space Optics - ICSO 2021, 2021, Online Only 


\section{International Conference on Space Optics-ICSO 2020}

Virtual Conference

30 March-2 April 2021

Edited by Bruno Cugny, Zoran Sodnik, and Nikos Karafolas
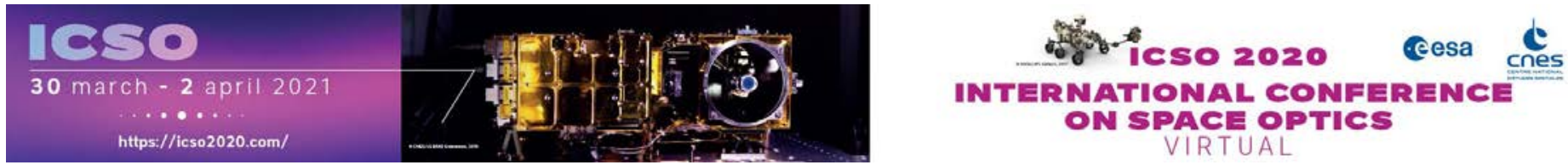

\section{A cost-effective ultra-high throughput space-based optical link}

\section{Cesa isso procedings denes}




\title{
A Cost-Effective Ultra-High Throughput Space-Based Optical Link
}

\author{
Emile Haddad*a , Hamid Limodehia ${ }^{\mathrm{a}, \mathrm{b}}$, Hongxin Chen ${ }^{\mathrm{a}}$, Francois Gonthier ${ }^{\mathrm{a}}$, Greg Schinn ${ }^{\mathrm{a}}$, Michel \\ Corriveau $^{\mathrm{a}}$, Dmitri Snejco ${ }^{\mathrm{a}}$, QiYang Peng ${ }^{\mathrm{a}}$, Kamel Tagziria ${ }^{\mathrm{a}}$, Wallace Clements ${ }^{\mathrm{a}}$ \\ aMPB Communications Inc., Pointe Claire, Québec, emile.haddad@mpbc.ca, 514-694-8751; \\ ${ }^{\mathrm{b}}$ INRS EMT 1650 blvd. Lionel-Boulet, Varennes, QC, Canada,
}

\begin{abstract}
High capacity throughputs are more and more requested by satellite owners, even before launching the first generation of optical constellations. MPB is developing a commercially-competitive photonics subsystem that increases the data throughput of a "free-space" optical link in a space environment. The objective is to build and demonstrate an optical subsystem suitable for deployment in space with a target capacity of $\geq 100 \mathrm{Gbit} / \mathrm{s}$ having a scalable architecture optimized for cost per Gbit, while maintaining acceptable (e.g. 10-4) pre-FEC bit error ratio (BER), high reliability, design flexibility.

The two most promising solutions for the 100Gbps links use either a suitably-adapted commercial $100 \mathrm{Gbps} \times 1 \mathrm{ch}$ transceiver (e.g. commercial Dual-Pol 28Gbaud, 4 bits/symbol) or wavelength-agile WDM $10 \mathrm{Gbps}$ x 10ch, or similar system (e.g. $12.5 \mathrm{Gbps} \times \mathrm{cch}$ ). The subsystem is based on the selected optimal architecture, convenient for space environment, and potentially comprising one or more of the "throughput-enhancing" possible approaches; such as the Modulation bitrate, Wavelength multiplexing (WDM), and Spectral efficiency. A large number of the performance parameters are also involved in the evaluation of the optimal solution, including: OSNR, Power at Rx, Mass and Volume, Cost, Complexity of the Software and Hardware to develop, Reliability/Redundancy, Power-Consumption and wall-plug Efficiency (W/Gbps), Signal Modulation, BER, and Stimulated Brillouin Scattering.

MPB plans to verify that the $100 \mathrm{G}$ commercial transceiver, a coherent module optimized for terrestrial use, is compatible with the harsh space environment. Moreover, its design needs to be modified (in collaboration with the manufacturer) in order to employ distinct Tx and Rx wavelengths. Although such an approach enables all data to be sent over a single wavelength, in the event of an e.g. Tx optical-amplifier failure all transmission capability would be lost. The coherent transceivers themselves are very complicated in design, but this development has already been carried out by the manufacturer for terrestrial applications.

The WDM option $10 \mathrm{G} \times 10 \mathrm{ch}$ has a larger mass, volume, and power per Gbps, however, the technology is based on MPB-developed boosters for space applications and offers higher redundancy (i.e. if one optical Tx amp fails, the other nine channels can still transmit). This option adds more complexity and cost since it needs to develop more software and hardware items. This development is useful for the other amplifiers with similar requirements from space primes. In addition, we are including a detailed study and prototyping of a space-borne Reconfigurable Optical Add-Drop Multiplexer (ROADM), which would enable greatly enhanced dynamic bandwidth allocation.
\end{abstract}

The two approaches (single-channel high BW vs multi-channel medium BW) have respective advantages and disadvantages.

Keywords: 100 Gbps Transmitter Optical Intersatellite link- satellite-Ground link, High power EDFA, *emile.haddad@mpbc.ca; phone 1514 694-8751; www.mpbc.com

\section{INTRODUCTION}

Satellite Constellations are launched in space mainly at Low Earth Orbit (LEO). In 2015, three main groups were competing to provide the internet from satellites through optical communications; Google, Facebook, SpaceX-Airbus, with a plan to have a global 5000-6000 satellites in a few constellations. Now they are about a dozen major players planning to populate the space with about 55,000 to 60,000 satellites by 2029 [1]. 
In parallel, the studies of intermediate liaisons between satellites and Earth such as balloons, airplanes, or drones are now assembled within a group called HAP(S) High Altitude Platforms or High-Altitude Pseudo-Satellites. Satellite primes are testing airplanes high at about 25-35 km in space (e.g. Zephyr from Airbus) as HAP. The market for optical intersatellite communications has evolved based on the growth in demand for bandwidth capacity.

RF communications is still a bottleneck for moving data at Internet speeds in space. The centimeter-long wavelengths of microwaves in high-frequency RF transmission bands result in widely diffracting beams that spread over hundreds of kilometers on the Earth when transmitted over $39,000 \mathrm{~km}$ from a satellite above in geosynchronous orbit (GEO). Increasing data transmission to speeds in excess of $100 \mathrm{~Gb} / \mathrm{s}$ requires a more concentrated signal at the target and higher transmit powers to deliver the same energy per bit to the receiver. Satellite services based on RF, offer limited bandwidth and have high latency, and they require licensing of the extremely crowded frequency spectrum.

Fiber optic cables provide the capacity and latency. However, the installation of fiber optic infrastructure is often impractical, inaccessible, and/or uneconomical in underserved or remote geographical regions. It is also not an option for transport vehicles such as aircraft and ships where the demand for internet access and associated services is also growing. Therefore, optical inter-satellite links offer the potential for "affordable terrestrial fiber quality service with global coverage" for:

- Remote geographical areas, where fiber optic technology is inaccessible or impractical to deploy

- Aircraft, where on-board demand for internet access and "Netflix" type broadcasts are desirable

- Marine, from internet and "Netflix" type access to travellers on cruises to mariners aboard fleets is desirable

- Disaster stricken areas, when hardwired infrastructure is critically damaged and it is necessary to restore services such as mobile phones and critical broadcasting in the shortest interval.

The growing internet market is driving the interest in optical satellite telecom, following the plans of Google, Facebook, SpaceX, Airbus, Telesat, and others, to invest in the development of large constellations using optical telecom. There are tremendous potential commercial applications, in particular, to connect a considerable percentage of the Earth's population to the Internet.

The first generation of satellite constellations using optical communications is planned for deployment in 2022 with service in 2025. While these constellations will offer Gbit capacity, there is already a desire to see terabit/s capacity, in order to seamlessly integrate with the existing terrestrial infrastructure.

It is expected that the $10 \mathrm{~W}$ optical amplifier based on Erbium and Erbium-Ytterbium Doped Fiber (EDFA) will permit more than 100 Gbps data transfer. The EDFAs are key devices in the optical communications in space with the following examples of applications:

- Optical Telecom satellite communications. Recently, there is a large increase in the importance of investment, Google, Facebook, SpaceX, Airbus are investing Billions\$:

- Satellite to HAP, the HAP being the liaison between the satellite and the ground segment

- Optical inter-satellite Link (LEO-LEO) and (LEO-GEO)

- Fast transfer of data close to real-time data from Earth Observation satellite images (a few minutes instead of 90 minutes currently with RF signal)

- Intra telecom satellite optical applications- Flexible telecom repeater with microwave photonic MxN crossconnect. The Optical Wideband Receiver (OWR) contract from ESA to Thales-Alenia-Space (TAS) led to the experimental definition of the parameters and then building the components (e.g. minimum amplification needed and maximum Noise acceptable). MPB participated in OWR as a subcontractor to TAS, the major task was to build a Medium Level Optical Amplifier (MLOA), containing 4 amplifiers with a 20-21 dB gain each, and $\pm 1 \mathrm{~dB}$ flatness requirement over $10 \mathrm{~nm}$ 1540-1558 nm. Two MLOAs were built and delivered to TAS/ESA

- Sensor application in non-Telecom satellites. MPB installed Fiber sensors demonstrator on Proba-2 to measure the temperature (Fiber-wireless multiplexing). It uses the first Erbium Doped Fiber Laser in space

- Various Instruments where very low noise is a must (e.g. MIRAS on SMOS)

- Non-Telecom Communication links in non-Telecom satellites, for example, a next-generation SMOS.

- Boost the optical signal in Photonics payloads

- Processing applications in non-Telecom satellites (mm-wave generation e.g. EO or THZ on Fiber). 


\section{OPTICAL INTERSATELLITE LINK BUDGET}

To validate the functionality of a transmitter for a fast data transfer, one main item to find is the number of photons getting in the unit time, e.g. $10^{-11}$ second for the $100 \mathrm{Gbps}$, is high enough to have an acceptable small Bit Error Rate (BER). This leads to the estimation of the link budget between the transmitter and the receiver. A simplified schematic of the inter-satellite link is presented in Figure 1.

It starts with a transceiver sending a small signal in the high gain amplifier called usually a "booster". For the Optical Intersatellite link and Optical to ground link the booster output power is between 1 and $10 \mathrm{~W}(1550 \mathrm{~nm})$. The signal is reduced by a large factor due to the dispersion in long distances in free space called the "Isotropic Space Loss" which is about $-260 \mathrm{~dB}$ for LEO links $(1300 \mathrm{~km})$ and $-290 \mathrm{~dB}$ for a GEO Link $(39770 \mathrm{~km})$ [2] Although these values are very large the signal is getting at the receiver point is a very small signal (down to $-48 \mathrm{dBm}$ ). A Low Noise Amplifier (called pre-amplifier) regenerates the signal and sends it in the input of the transceiver to repeat the transmission.

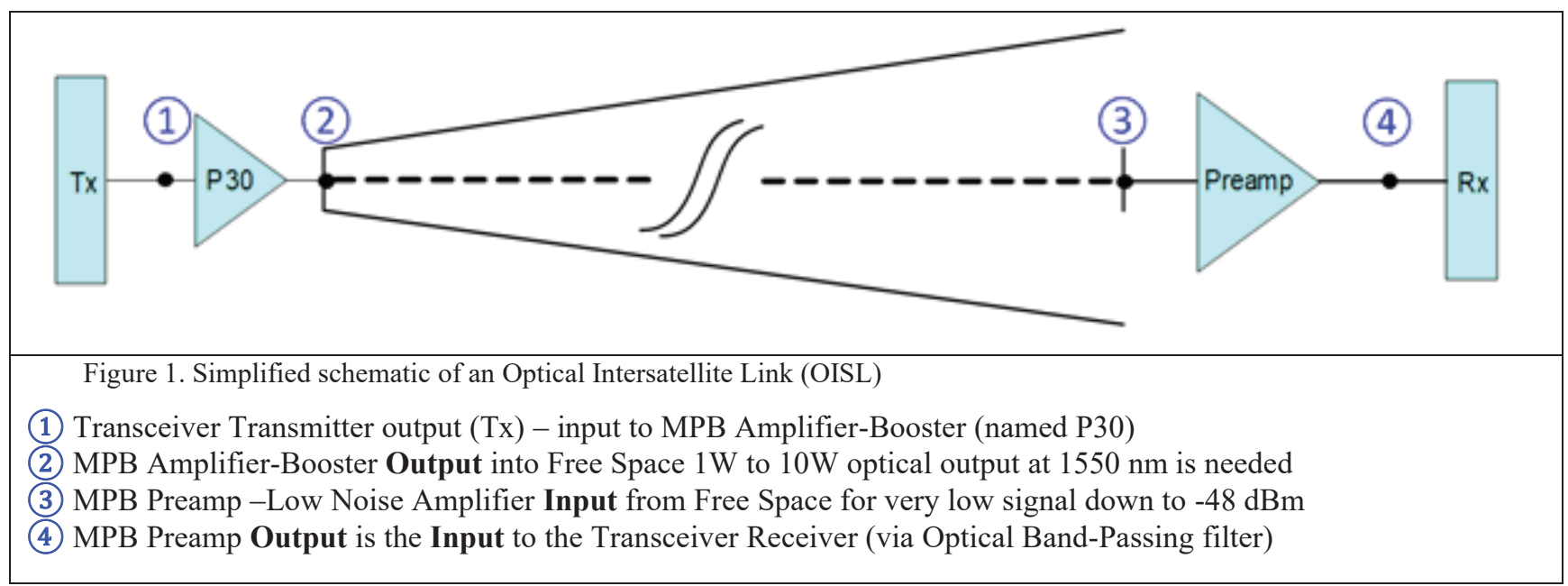

Various parameters need to be known in o evaluate the link budget we consider various involved parameters:

\section{A) Power related parameters}

- Bit/Symbol -depends on the modulation used (see Table 1)

- Number of photons/symbol received at the next relay point (3)

- Transmitter electrical power/symbol ( $\mathrm{mW}_{\mathrm{e}} / \mathrm{Gbps}$ ) (Wall plug efficiency) at (3)

- Transmitter Optical signal power ( $\mathrm{dBm}$ ) at (3) (compare with a commercial $100 \mathrm{Gbps}$ transceiver at $-28 \mathrm{dBm}$ )

- Optical Signal to Noise Ratio (OSNR) at (4) (compare with a commercial 100Gbps transceiver at $12 \mathrm{~dB}$ )

- Total electrical power/symbol ( $\left.\mathrm{mW}_{\mathrm{e}} / \mathrm{Gbps}\right)$ at (4)

- BER/SER (depends on the modulation type and rate)

B) Other parameters

- Redundancy

- Optical Cross Connection (case of $10 \lambda$ x10Gbps)

- Stimulated Brillouin Scattering (at high power: $10 \mathrm{~W}$ )

- Size, Weight, and Power (SWaP)

- Reliability - Failure In Time (FIT)

- Compatibility with space environment (outgassing, thermal cycling, radiation) 
To note, the term "GigaBit Per Second" or Gbps is used, the important parameter for the data transfer is the "Giga Symbol Per Second". The Bit/Symbol depends on the used modulation technique. Table 1 gives the number of Bit/Symbol for some frequently used modulation techniques. For example, most of the current commercial fast transceivers claiming the capability of $100 \mathrm{Gbps}$ rate, are in fact at $28 \mathrm{Gbps}$, with a DP-QPSK modulation transferring at 112 Giga-Symbol per second.

Table 1: Number of Bit/Symbol for some frequently used modulation techniques

\begin{tabular}{|l|c|c|c|l|l|}
\hline $\begin{array}{l}\text { Modulation } \\
\text { Techniques }\end{array}$ & $\begin{array}{l}\text { On-Off } \\
\text { Keying } \\
\text { (OOK) }\end{array}$ & $\begin{array}{l}\text { Binary phase- } \\
\text { shift keying } \\
\text { (BPSK) }\end{array}$ & $\begin{array}{l}\text { Differential } \\
\text { Phase Shift } \\
\text { Keying (DPSK) }\end{array}$ & $\begin{array}{l}\text { Differential Quadrature } \\
\text { Phase Shift Keying } \\
\text { (DQPSK) }\end{array}$ & $\begin{array}{l}\text { Dual-polarization } \\
\text { Quadrature } \\
\text { Keying (DP-QPSK) }\end{array}$ \\
\hline $\begin{array}{l}\text { Number of } \\
\text { Bit/Symbol }\end{array}$ & 1 & 1 & 1 & 2 & 4 \\
\hline
\end{tabular}

The link budget relates the power at the Receiver is related to the Transmitter power, its evaluation is needed to verify the required power at the transmitter level, to determine the number of photons per unit time (bit), arriving at the entrance of the receiver (pre-amplifier). The following equation is commonly used by the satellite primes to evaluate the required transmitter power, the size of the transmitter and receiver telescopes, and the requirement of the preamplifier:

\section{$P_{\mathrm{R}}=P_{T} G_{T} \eta_{T} \eta_{\mathrm{ATM}} L_{\mathrm{FS}} L_{\mathrm{p}} L_{\mathrm{SI}} G_{\mathrm{R}} \eta_{\mathrm{R}} \eta_{\mathrm{C}}$}

$P_{\mathrm{R}}$ is the received optical power, detected at distance $L$

$P_{T}$ is the transmitted average optical power with wavelength $\lambda$

$G_{T}=\left(\pi D_{T} / \lambda\right)^{2}$ and $G_{\mathrm{R}}=\left(\pi D_{\mathrm{R}} / \lambda\right)^{2}$ are the transmitter and receiver gains, respectively

( $D_{T}$ and $D_{\mathrm{R}}$ are the diameters of the transmitter and receiver telescope, respectively)

$\eta_{T}, \eta_{\mathrm{R}}$, and $\eta_{\mathrm{C}}$ are the transmitter, receiver, and fiber coupling efficiencies, respectively,

$\eta_{\text {АтM }}$ is the atmospheric attenuation in the case of Satellite Ground or Ground-Satellite;

$L_{\mathrm{FS}}=(\lambda / 4 \pi L)^{2}$ is the free-space loss, $\mathrm{L}$ is the distance Transmitter-Receiver

$L_{\mathrm{p}}=\exp \left(-G_{T} \theta^{2}{ }_{\mathrm{BW}}\right)$ corresponds to the pointing errors, $\theta_{\mathrm{Bw}}$ is the pointing jitter

$L_{\mathrm{SI}}$ is the scintillation-induced errors when the light is transmitted through the Earth Atmosphere

For a fixed distance, to increase the signal at the receiver $\left(P_{\mathrm{R}}\right)$ we can increase the transmitter power, $\left(P_{T}\right)$, the diameter of the transmitter telescope $\left(D_{T}\right)$, and that of the receiver $\left(D_{\mathrm{R}}\right)$. In most cases, they are the other parameters related to the efficiencies and pointing errors

In 2019 and 2020 ESA accorded two contracts in parallel, "High Throughput Optical Network (Hydron), Artes ScyLight" within Hydron subprogram (ESA AO/1-9814/19/UK/AB); to study the feasibility of 100 Gbps with 10 wavelengths each at $10 \mathrm{Gbps}$. The final objective is to compare the advantages and disadvantages of the two methods:

- One transmitter at one channel (wavelength) $10 \mathrm{~W}, 1 \lambda \times 100 \mathrm{Gbps}$

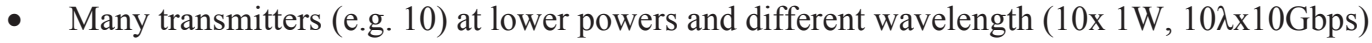

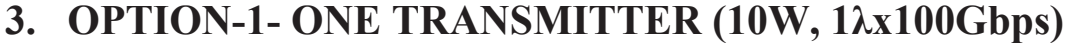

\subsection{Review of current fast transfer with one wavelength}

To achieve image transfers from satellites, close to real-time, with low Bit Error Rates-(BER), a data transfer rate should be of the order or higher than $100 \mathrm{Gbps}$. To achieve this level of transfer speed the number of photons per unit time (1011 second) should be high enough to permit a low Bit Error Rate (BER)

Table 2 gives an example of current studies of space-related optical link and their date rate transmission. 
Table 2: Example of studies and the relative data transfer for 1 wavelength transmitter

\begin{tabular}{|c|c|c|c|c|c|}
\hline Reference Work & Modulation Technique & Link & $\begin{array}{c}\text { Tx Power } \\
\text { (W) }\end{array}$ & $\begin{array}{c}\text { Max transfer } \\
\text { Symbol/sec }\end{array}$ & $\begin{array}{c}\text { Distance } \\
(\mathbf{k m})\end{array}$ \\
\hline $\begin{array}{l}\text { Optical Link Study Group OLSG } \\
(2012) ;[2]\end{array}$ & OOK, & LEO-Ground & 0.5 & 10 & 1300 \\
\hline $\begin{array}{l}\text { Optical Link Study Group OLSG } \\
(2012) ;[2]\end{array}$ & DPSK, & GEO-Ground & & 10 & 39,770 \\
\hline DLR, Barrios et al. (2018); [3] & DPSK or BPSK & Small LEO-GEO Relay & 3 & 10 & 40,000 \\
\hline DLR, Barrios et al. (2018); [3] & DPSK or BPSK & Big LEO- GEO Relay & 5 & 10 & 45,000 \\
\hline DLR, Barrios et al. (2018); [3] & DPSK or BPSK & UAV to GEO Relay & 50 & 10 & 35,980 \\
\hline DLR, Barrios et al. (2018); [3] & DPSK or BPSK & GEO Relay to Ground & 10 & 10 & 38,394 \\
\hline DLR, Giggenbach et al. (2018); [4] & OOK & $\begin{array}{c}\text { LEO (Earth } \\
\text { Observation) to Ground }\end{array}$ & 1 & 10 & $700-1000$ \\
\hline DLR, Giggenbach et al. (2018); [4] & OOK & $\begin{array}{l}\text { Ground to LEO (Earth } \\
\text { Observation) }\end{array}$ & 10 & 10 & $700-1000$ \\
\hline $\begin{array}{l}\text { EDRS-Copernicus -Sentinel-1 (2019); } \\
\text { [5] Demonstrated on satellite }\end{array}$ & O-QPSK & LEO-GEO & 2.5 & 1.8 & 45,000 \\
\hline NASA, Warner et al. (2019); [6] & DPSK & GEO-GEO & 5 & 55 & 73,000 \\
\hline NASA, Warner et al. (2019); [6] & DPSK & GEO-GEO & 1 & 11 & 73,000 \\
\hline NASA, Warner et al. (2019); [6] & DPSK & LEO-GEO & 5 & 200 & 42,880 \\
\hline NASA, Warner et al. (2019); [6] & DPSK & LEO-GEO & 2.5 & 100 & 42,880 \\
\hline NASA, Warner et al. (2019); [6] & DPSK & GEO-Ground & 5 & 1,524 & 35,790 \\
\hline NASA, Warner et al. (2019); [6] & DPSK & GEO-Ground & 2.5 & 762 & 35,790 \\
\hline NASA, Warner et al. (2019); [6] & DPSK & GEO-Ground & 0.5 & 152 & 35,790 \\
\hline Padhy et al. (2018); [7] & DPSK + Manchester coding & LEO-MEO & 1 & 40 & 19,100 \\
\hline Sivakumar et al. (2019); [8] & $\begin{array}{c}\text { PDM-QOSK with coherent } \\
\text { detection and DSP }\end{array}$ & LEO-GEO & 1 & 160 & 40,000 \\
\hline
\end{tabular}

NASA had performed studies [6;9] evaluating the Maximum Data Rate Achievable and Power Requirements for three cases of optical links: Relay to Ground (35,790 km), LEO-GEO (42,880 km), and GEO-GEO (73,000 km). For each link three levels of transmitter power were considered; $0.5 \mathrm{~W}, 1$ or $2.5 \mathrm{~W}$, and $5 \mathrm{~W}(1550 \mathrm{~nm})$. Four sets of transmitter and receiver telescopes were considered for each study, their diameters were selected based on previous or proposed telescopes for NASA missions. The $100 \mathrm{Gbps}$ was possible for the LEO GEO only with the set of largest telescopes, and the highest transmission was $55 \mathrm{Gbps}(5 \mathrm{~W}$ transmitter) for the GEO-GEO Link. The studies show the need for a higher power (10W) transmitter to have a reliable $100 \mathrm{Gbps}$ at LEO-GEO or GEO-GEO link

It was not possible to push for a quantitative comparison between the various studies, each having its own assumptions and estimation of the efficiency parameters and pointing errors, in addition to very different telescope diameters considered.

\subsection{Development of the $10 \mathrm{~W}$ Amplifiers in the $1550 \mathrm{~nm}$ range at MPB}

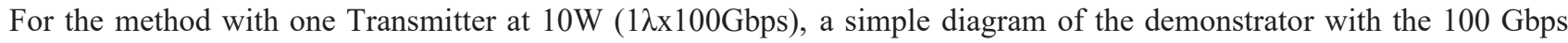
transceiver is:

Transceiver-Output $(0-1 \mathrm{dBm})=>$ MPBC $10 \mathrm{~W}$ Amplifier $=>$ VOA(s)

$=>$ MPBC Low-Noise-Amplifier $=>$ Input-Transceiver 
The demonstrator with the 100 Gbps transceiver is being built in collaboration with the supplier of such a commercial product. This product is still in the prototype stage, MPB will perform its space qualification during the collaboration.

MPB developed a family of EDFA amplifiers (1550 nm) at 1-3W output power, presented at ICSO-2018 [9]. Recently a preliminary space-qualified $10 \mathrm{~W}$ Polarization Maintaining Amplifier based on Erbium-Ytterbium Doped Fiber. The amplifier characterization ( Table 3, Figure 2) is presented in a paper at ICSO 2020 [10]. At the $10 \mathrm{~W}$ level, the thermal dissipation of the heat generated by the electronics and the laser diode pumps at $940 \mathrm{~nm}$ becomes the main challenge for a space-qualified amplifier, with limited surfaces, volume, and mass. To have the amplifier functional between $-20^{\circ} \mathrm{C}$ and $50^{\circ} \mathrm{C}$ MPB had to use an Innovative Proprietary Method of the spool design for the active fibers. Work is progressing to have a larger range, at least between $-35^{\circ} \mathrm{C}$ and $+65^{\circ} \mathrm{C}$.

The optical loss signal in space of the order of 60-72 dB, estimated from the Link budget (previous section) can be represented by Variable Optical Attenuators (VOA).

Table 3: Experimental Efficiency 10 W-PM EDFA

\begin{tabular}{|l|c|c|}
\hline \multicolumn{1}{|c|}{ Loss Power (W) } & Loss Power (W) & Last (2020) \\
\hline Nominal output Power(W) & - & $\mathbf{1 0 . 4}$ \\
\hline Er:Yb-doped fiber efficiency & $\mathbf{2 5}$ & $\mathbf{3 2 \%}$ \\
\hline Combiner efficiency signal & $\mathbf{0 . 0 7}$ & $\mathbf{9 3 \%}$ \\
\hline Combiner pump transmission & $\mathbf{1 . 5}$ & $\mathbf{9 5 \%}$ \\
\hline Isolator efficiency & $\mathbf{8 9 \%}$ \\
\hline Laser Diode Pump power & $\mathbf{3 5 . 5}$ & $\mathbf{5 1 . 5 \%}$ \\
\hline Driver and control board efficiency & $\mathbf{1 5}$ & $\mathbf{8 3 \%}$ \\
\hline Total electrical power needed(W) & - & $\mathbf{8 7}$ \\
\hline Total Loss (W) & $\mathbf{7 7}$ & $\mathbf{8 9 . 6 \%}$ \\
\hline Wall-plug efficiency & - & $\mathbf{1 1 . 4} \%$ \\
\hline
\end{tabular}

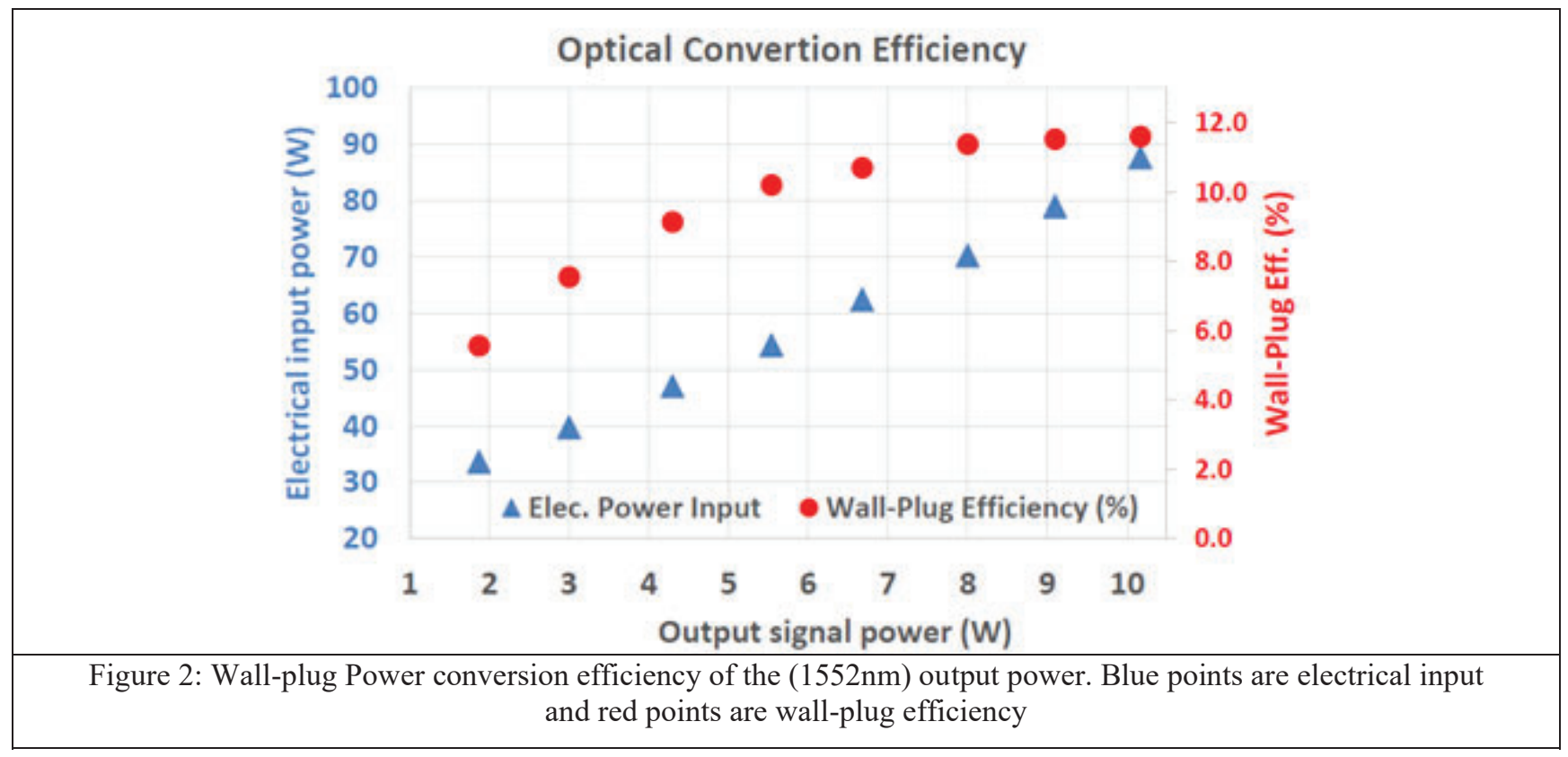




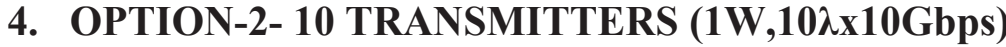

\subsection{Review of current fast transfer with many wavelengths}

Table 4 gives some studies examples of very high data transfer rate up to Terabit/second (Tbps) and the modulation techniques used to reach such rates. The EDRS relatively lower data rate is the one proposed to be used on satellites.

Table 4: Example of studies and the relative data transfer for lower power amplifiers with many wavelengths

\begin{tabular}{|c|c|c|c|c|c|}
\hline Reference Work & Modulation Technique & Link & $\begin{array}{c}\text { Tx Power } \\
(\mathbf{W})\end{array}$ & Max transfer Symbol/sec & $\begin{array}{c}\text { Distance } \\
(\mathrm{km})\end{array}$ \\
\hline $\begin{array}{l}\text { EDRS-Copernicus - } \\
\text { Sentinel-1 (2019) [5] }\end{array}$ & O-QPSK & $\begin{array}{l}\text { LEO-LEO, } \\
\text { LEO-GEO, } \\
\text { UAV-GEO }\end{array}$ & 5 & $4 \lambda \times 1.8=5.6 \mathrm{Gbps}$ & $\begin{array}{l}1000- \\
45000\end{array}$ \\
\hline Sumathi (2020) [12] & $\begin{array}{l}\text { Hybrid WDM-PDM with } \\
\text { orthogonal modulation scheme } \\
\text { CSRZ-DQPSK - PolSK }\end{array}$ & LEO -GEO & 1 & $\begin{array}{c}16 \times 2 \mathrm{SOP} \times 120 \mathrm{Gbps}= \\
3.84 \mathrm{Tbps}\end{array}$ & 58,000 \\
\hline $\begin{array}{l}\text { Kaur et al. (2018) } \\
{[13]}\end{array}$ & $\begin{array}{l}\text { WDM link with Alternate mark } \\
\text { inversion (AMI) scheme }\end{array}$ & LEO-LEO & 1 & $\begin{array}{l}64 \lambda \times 40 \mathrm{Gbps} \\
=2.56 \mathrm{Tbps}\end{array}$ & 2,500 \\
\hline Gill et al. (2019 [14] & $\begin{array}{l}\text { Mode Division Multiplexing } \\
\text { (MDM) with DQPSK scheme }\end{array}$ & LEO-LEO & 1 & $\begin{array}{c}64 \text { spatial modes } x 40 \mathrm{Gbps} \\
=2.56 \mathrm{Tbps}\end{array}$ & 3,750 \\
\hline Poliak (2018) [15] & DWDM channels & $\begin{array}{l}\text { Uplink } \\
\text { Ground-GEO }\end{array}$ & 1.7 & $\begin{array}{c}40 \lambda \times 43 \mathrm{Gbps} \\
=1.72 \mathrm{Tbps}\end{array}$ & 40,000 \\
\hline
\end{tabular}

A detailed comparison of various modulation techniques, with some explanation, an estimation of BER and their capabilities up to $400 \mathrm{Gbps}$ are given by Mohapatra et al. [16]

\subsection{Present Development of $10 \lambda \times 10$ Gbps at MPB}

For the method with 10 transmitters: MPB completed a detailed optical design of Reconfigurable Optical Add-Drop Multiplexer (ROADM) for Space Optical Cross Connection Links (OXC), based on DWDM, having 10-ITU channels for a total $100 \mathrm{Gbps}$.

The ROADM is connecting in bi-direction, with Add/Drop. We consider 4 satellites each in one direction noted East (E), South (S), West (W), and North (N), with a fifth option to the Add/Drop to Ground (Figure 3). The OXC design permits switching signals from one direction to any other for two channels having the same ITU wavelengths or two different wavelengths. The Add/Drop signals - can add one or two ground data signals or drop one or two ROADM data signals into and from any direction and any DWDM (wavelength) channel among the ten $\lambda$-channels, respectively (Figure 4).

The optical signal power flatness between the $\lambda$-channels is controlled by power monitors, including a $2-5 \%$ tap photodetector (PIN-photodiode) and VOAs. For $10 \lambda \times 10 \mathrm{Gbps}$, various suppliers were contacted.

Although all the optical components are available as commercial products, the price of optical components (Optical switches, MUX/DEMUX, couplers, VOAs, channel-power-monitor, DFB-transmitters, and photodetectors) is of the order of $200 \mathrm{~K} €$, without the electronics that monitor these components.

MPB reduced the number of components (e.g. wavelengths) to build a simplified prototype significantly representative of ROADM-OXC at an acceptable cost. This exercise permits MPB to keep a minimum of know-how to stay within the best international companies providing the ROADM-OXCs.

Figure 5 illustrates the demonstrator to build, it was reduced to $2 \times 2$ Cross Connection in all direction between two satellites e.g. satellite East (E) and Satellite West (W). 

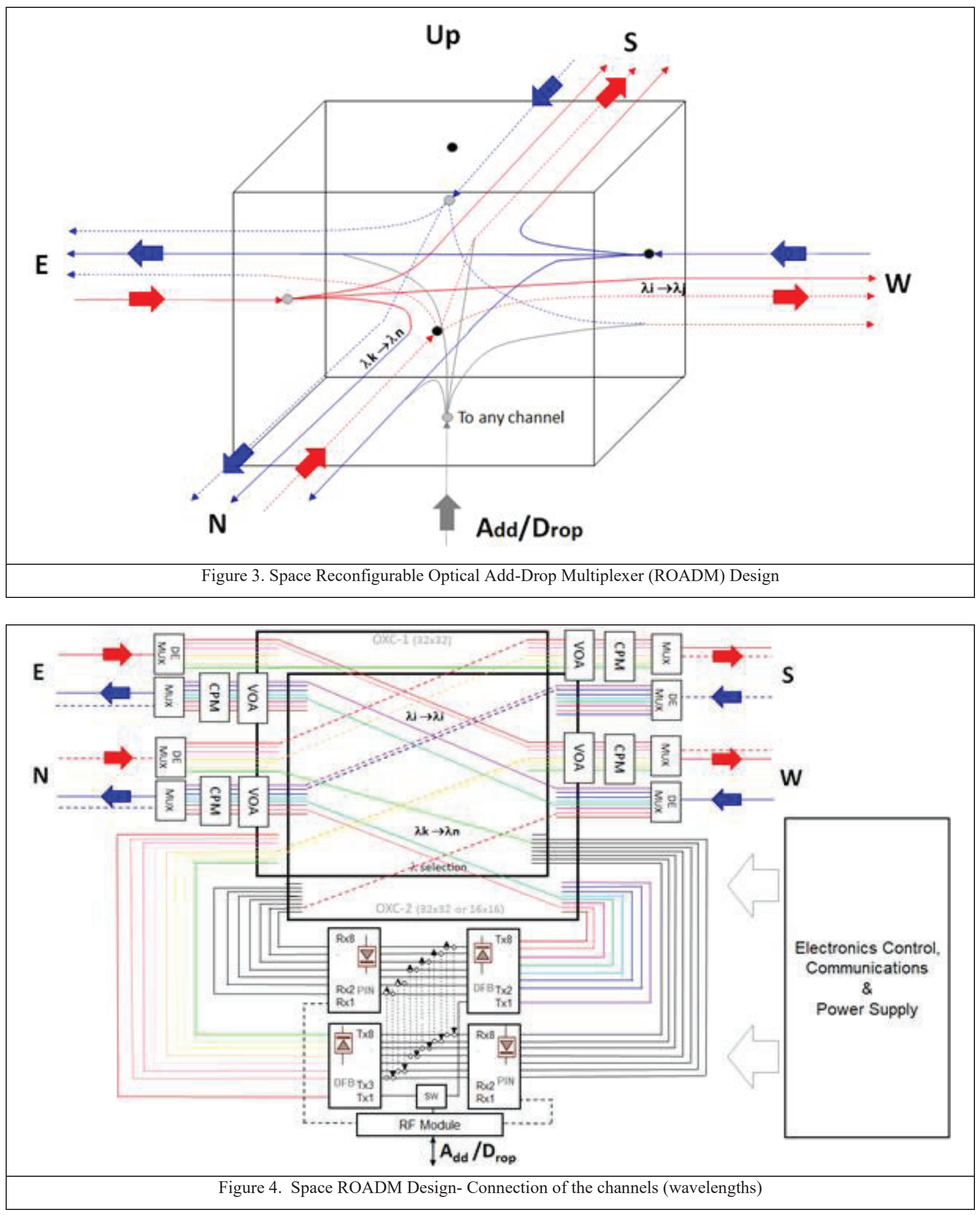


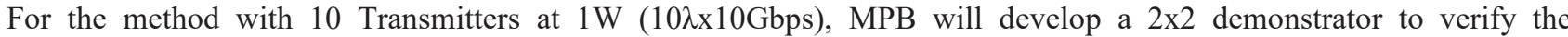
technology and compare the experimental results to available satellite data at close rate e.g. those from EDRS, and works developed at the NASA or ESA.

A simple diagram of the demonstrator with $2 \times 2$ Cross Connection, and 10 Gbps Transceivers is:

\section{2x 10GbpsTransceivers-Output $(0-1 \mathrm{dBm})=>$ 2xMPBC $1 \mathrm{~W}$ Amplifier $=>$ VOA(s) \\ $\Rightarrow$ 2x2 SWITCH $=>$ MPBC Low-Noise-Amplifier => Input- 2x 10 Gbps Transceivers}

MPB is in the process of building the $1 \mathrm{~W}(2 \lambda \times 10 \mathrm{Gbps})$, demonstrator using MPB amplifiers of $1 \mathrm{~W}$ at the transmitters and the Low Noise Amplifier at the receivers

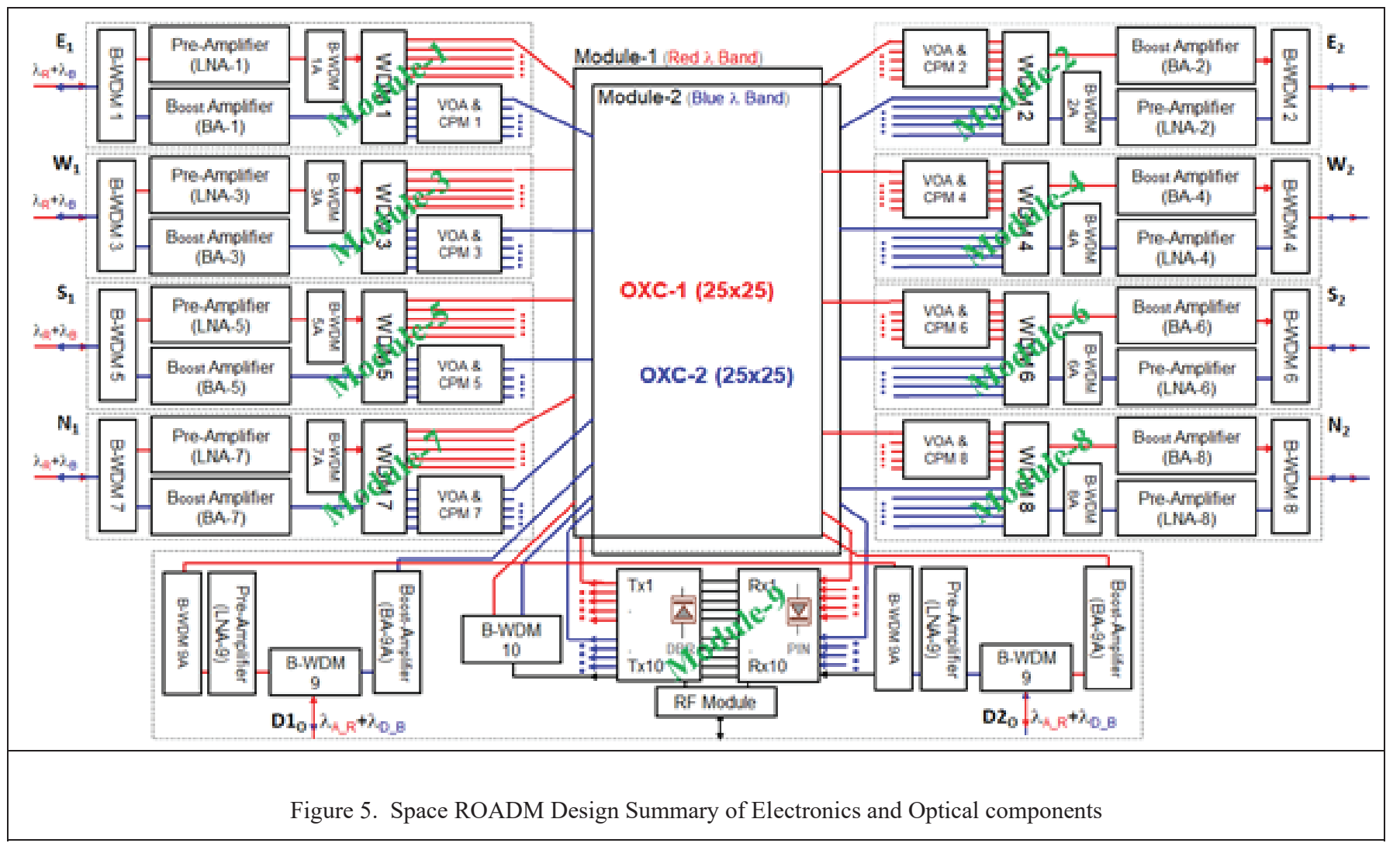

\section{COMPARISONS OF TRANSMITTERS: $1 \mathrm{X}(10 \mathrm{~W}, 1 \lambda X 100 \mathrm{GBPS}) \mathrm{VS}$ $10 X(1 \mathrm{~W}, 10 \lambda \times 10 G B P S)$}

In the next step, we will compare the performance of the two methods ( $1 \lambda x 10 \mathrm{Wx} 100 \mathrm{Gbps})$ and $(10 \lambda \times 1 \mathrm{Wx} 10 \mathrm{Gbps})$. A preliminary comparison is given in Table 5 . The $10 \mathrm{~W}$ version seems very well needed unless the telescope diameters at the receiver and transmitters are increased to $>20 \mathrm{~cm}$ each. 
Table 5: Comparison of the two methods $1 \lambda x 10 \mathrm{Wx} 100 \mathrm{Gbps}$ with $10 \lambda \mathrm{x} 1 \mathrm{Wx} 10 \mathrm{Gbps}$

\begin{tabular}{|c|c|c|}
\hline Parameter & $1 \lambda \times 10 \mathrm{Wx100Gbps}$ & $10 \lambda \times 1 \mathrm{Wx} 10 \mathrm{Gbps}$ \\
\hline Redundancy & Only one transmitter & $\begin{array}{l}10 \text { transmitters, if one fails the others continue to be } \\
\text { functional }\end{array}$ \\
\hline $\begin{array}{l}\text { Bit Error Rate or } \\
\text { Symbol Error Rate }\end{array}$ & Lower & Higher \\
\hline Modulation techniques & $\begin{array}{l}\text { Simple techniques are convenient in most } \\
\text { applications }\end{array}$ & Complex techniques with increased bit/symbol are needed \\
\hline Max Distance & $\begin{array}{l}\text { More convenient as distance increase e.g. } \\
\text { for GEO-GEO } 73,000 \mathrm{~km}\end{array}$ & $\begin{array}{l}\text { Less convenient as the distance increases } \\
\text { LEO-LEO and some LEO-GEO }\end{array}$ \\
\hline Other application than & $\begin{array}{l}\text { Lidar (CO2), Ranging, 3D-Imaging, } \\
\text { Altimetry, Topology, }\end{array}$ & $\begin{array}{l}\text { MxN intra-satellite optical link (e.g. Optical Microwave } \\
\text { cross-connection [17] }\end{array}$ \\
\hline $\begin{array}{l}\text { Space qualification } \\
\text { status }\end{array}$ & $\begin{array}{l}\text { To complete the space qualification of the } \\
10 \mathrm{~W} \text { transmitter } \\
\text { Space qualify the } 100 \mathrm{Gbps} \text { transceiver }\end{array}$ & $\begin{array}{l}\text { We can find suppliers of space-qualified components } \\
\text { included in the demonstrator }\end{array}$ \\
\hline
\end{tabular}

\section{ACKNOWLEDGMENTS}

The authors gratefully acknowledge the financial support of the Canadian Space Agency to develop this study

\section{REFERENCES}

[1] Oltrogge Dan, “The Space Safety Coalition in the context of international space cooperation”, UN COPUOS STSC 5 Feb 2020.

[2] OLSG 2012; Interagency Operations Advisory Group -Optical Link Study Group, Optical Link Study Group -Final Report 5 June 2012 (OLSG) Report\# IOAG.T.OLSG.2012.V1

[3] R. Barrios, B. Matuz and R. Mata-Calvo, "Ultra-High Speed Data Relay Systems". Chapter 12, in S. K. Sharma, S. Chatzinotas and P. Arapoglou, [Satellite communications in the 5G era,] London: The Institution of Engineering and Technology (IET), 2018, pp. 341-373

[4] D. Giggenbach, F. Moll, C. Schmidt, C. Fuchs, A. Shrestha; "Optical on-off keying data links for low Earth orbit downlink applications" Chapter 11, in S. K. Sharma, S. Chatzinotas and P. Arapoglou, [Satellite communications in the 5G era,] London: The Institution of Engineering and Technology (IET), 2018, pp. 307-339

[5] Copernicus: Sentinel-1 — The SAR Imaging Constellation for Land and Ocean Services

\section{https://directory.eoportal.org/web/eoportal/satellite-missions/c-missions/copernicus-sentinel-1\#foot38\%29}

[6] J. H.D. Warner et al.; "Optical Relay for Future NASA Geosynchronous Orbiting Satellite for High Data Rate Links to NASA User Missions", NASA Report 20190000302.

[7] Padhy, J., \& Patnaik, B. (2018). DPSK and Manchester coding for inter-satellite optical wireless communication systems. In IEEE 5th international conference on emerging technologies and applied sciences, 22-23 Nov, 2018, Bangkok, Thailand.

[8] P. Sivakumar, M. Singh, J. Malhotra, V. Dhasarathan; "Performance analysis of 160 Gbps single-channel PDMQPSK based inter-satellite optical wireless communication (IsOWC) system"; Wireless Networks; Springer 2020; 
doi.org/10.1007/s11276-020-02287-2(0 [Park 2019] Elizabeth A. Park; Donald Cornwell; David Israel NASA's Next Generation >100 Gbps Optical Communications Relay NASA Report 20190030264

[9] E. A. Park; D. Cornwell; D. Israel; "NASA’s Next Generation >100 Gbps Optical Communications Relay"; NASA Report 20190030264.

[10] F. Gonthier, V. Poenariu, J. Chu, D. Snejko, J. Lavoie, P. Murzionak, E. Haddad; "1550-nm combined transmission booster amplifier and receiver preamplifier for satellite to satellite laser communication"; Proc. SPIE 11180, International Conference on Space Optics — ICSO 2018, 1118010 (12 July 2019); doi: 10.1117/12.2535955

[11] E. Haddad, H. Limodehi, Q. Peng, K. Tagziria, V. Poenariua, P. Murzionak, G. Schinn, N. Karafolas, C. Bringer; "Space Qualification of a 10W single-mode PM optical amplifiers in the 1.5- $\mu \mathrm{m}$ region"; ICSO 2020

[12] K. Sumathi, M. Balasaraswathi, C. S. Boopathi, M. Singh, J. Malhotra, V. Dhasarathan: "Design of 3.84 Tbps hybrid WDM-PDM based inter-satellite optical wireless communication (IsOWC) system using spectral efficient orthogonal modulation scheme" Journal of Ambient Intelligence and Humanized Computing; https://doi.org/10.1007/s12652-020-01691-y

[13] Kaur, R., \& Kaur, H. Comparative analysis of chirped, AMI and DPSK modulation techniques in IS-OWC system. Optik, vol.154 (2018) p 755-762.

[14] Gill, H., Walia, G., \& Grewal, N.; "Performance analysis of mode division multiplexing IS-OWC system using Manchester, DPSK and DQPSK modulation techniques". Optik, 177, (2019)93-101.

[15] J. Poliak, R. Mata Calvo, F. Rein; "Demonstration of $1.72 \mathrm{Tbit} / \mathrm{s}$ optical data transmission under worst-case turbulence conditions for ground-to-geostationary satellite communications"; IEEE Communications Letters (2018), DOI 10.1 109/LCOMM.2018.2847628

[16] S. K. Mohapatra, R. R. Choudhury, R. Bhojra, P. Das; "Performance Analysis and Monitoring of Various Advanced Digital Modulation and Multiplexing Techniques of F.O.C within and beyond 400 Gbps"; International Journal of Computer Networks \& Communications (IJCNC) Vol.6, (2014) p159-181.

[17] S. Roux, T. Colombo, M. Aveline, M. Sotom, B. Benazet, M. Picq, H. Leblond; "Advanced photonic payloads for broadband telecom satellites : Integration and tests of a representative repeater demonstrator"; Proc. SPIE 11180, International Conference on Space Optics - ICSO 2018, 111804R (12 July 2019); doi: 10.1117/12.253609, Edited by Zoran Sodnik, Nikos Karafolas, and Bruno Cugny 